Article

\title{
Characterization of the Weimberg Pathway in Caulobacter crescentus
}

\author{
Henrik Almqvist ${ }^{1, *(\mathbb{D})}$, Sara Jonsdottir Glaser ${ }^{1,+}+(\mathbb{D})$, Celina Tufvegren ${ }^{2}(\mathbb{B})$, Lisa Wasserstrom ${ }^{2}$ \\ and Gunnar Lidén 1 \\ 1 Department of Chemical Engineering, Lund University, P.O. Box 124, SE-221 00 Lund, Sweden; \\ sara.jonsdottir_glaser@biotek.lu.se (S.J.G.); gunnar.liden@chemeng.lth.se (G.L.) \\ 2 Applied Microbiology, Department of Chemistry, Lund University, P.O. Box 124, SE-221 00 Lund, Sweden; \\ celina.tufvegren@tmb.lth.se (C.T.); lisa.wasserstrom@tmb.lth.se (L.W.) \\ * Correspondence: henrik.almqvist@chemeng.lth.se; Tel.: +46-46-2228278 \\ + Current address: Division of Biotechnology, Department of Chemistry, Lund University, P.O. Box 124, \\ SE-221 00 Lund, Sweden.
}

Received: 7 May 2018; Accepted: 9 June 2018; Published: 12 June 2018

\begin{abstract}
Caulobacter crescentus is a gram-negative bacterium that can utilize xylose as a substrate using the Weimberg pathway, which converts xylose to $\alpha$-ketoglutarate in five steps without carbon loss. This is an interesting pathway for heterologous expression in other organisms in order to enable xylose utilization in biorefinery processes. C. crescentus was grown on xylose, arabinose and glucose, and maximum specific growth rates determined for the three substrates were $0.11 \mathrm{~h}^{-1}, 0.05 \mathrm{~h}^{-1}$, and $0.15 \mathrm{~h}^{-1}$ respectively. Growth was found to be significantly inhibited at sugar concentration of $20 \mathrm{~g} \mathrm{~L}^{-1}$, shown primarily by an increased lag phase. Enzyme activity assays showed that the Weimberg pathway was active in cells grown, not only on xylose but also on arabinose. No activity was found for growth on glucose. Furthermore, substantial amounts of $\alpha$-ketoglutarate-up to a yield of $0.4 \mathrm{~g} \mathrm{~g}^{-1}$ — was excreted during growth on xylose, but no other extracellular intermediates in the Weimberg pathway were detected during growth on xylose. Apparently, C. crescentus is not well adapted for efficient growth on high xylose levels, and responds by an extended lag phase and secretion of $\alpha$-ketoglutarate.
\end{abstract}

Keywords: Caulobacter crescentus; Weimberg pathway; xylose; arabinose; physiological characterization; enzyme activity

\section{Introduction}

Caulobacter crescentus is an aquatic gram-negative bacterium, first described by [1] as Caulobacter vibrioides. The organism has been of interest for two main reasons; (a) its unusual cell cycle, and (b) its xylose degradation pathway. The cell cycle of $C$. crescentus involves two very different morphological forms, a motile swarmer cell and a non-motile stalked cell, making it a powerful model organism for studies of prokaryotic cell cycling [2-4]. The genetics of C. crescentus has been studied and the genome was fully sequenced by Nierman and co-workers [5]. The regulation and expression of the genes involved in replication has been reviewed by Curtis and Brun [3].

The aquatic natural environment of $C$. crescentus is nutrient poor. The ability of $C$. crescentus to utilize a wide range of substrates such as glucose, xylose, glucuronic acid, lactose, gluco-oligosaccharides and long-chain fatty acids is therefore important for its survival [6-10]. With respect to xylose metabolism, it is known that C. crescentus holds the Weimberg pathway [11]. The Weimberg pathway, first described in Pseudomonas fragi [12], is a rare pathway for xylose metabolism, found in only a handful of organisms [11]. The pathway consists of five enzymes that convert xylose to $\alpha$-ketoglutarate (Figure 1). 
First, xylose is reduced resulting in xylonolactone by an $\mathrm{NAD}^{+}$-dependent xylose dehydrogenase $(\mathrm{XylB})$ and the xylonolactone is subsequently hydrolyzed to xylonate by xylonolactone lactonase $(\mathrm{XylC})$ by the opening of the lactone ring. Subsequently, xylonate is dehydrated by xylonate dehydratase (XylD) into 2-keto-3-deoxy-xylonate which in turn is dehydrated by 2-keto-3-deoxy-xylonate dehydratase $(\mathrm{XylX})$ to $\alpha$-ketoglutarate semialdehyde. Finally, $\alpha$-ketoglutarate semialdehyde is reduced to $\alpha$-ketoglutarate by an $\mathrm{NAD}^{+}$-dependent $\alpha$-ketoglutarate semialdehyde dehydrogenase (XylA). Through the Weimberg pathway xylose can be converted to $\alpha$-ketoglutarate without loss of carbon, combined with a gain of 2 equivalents of NADH.

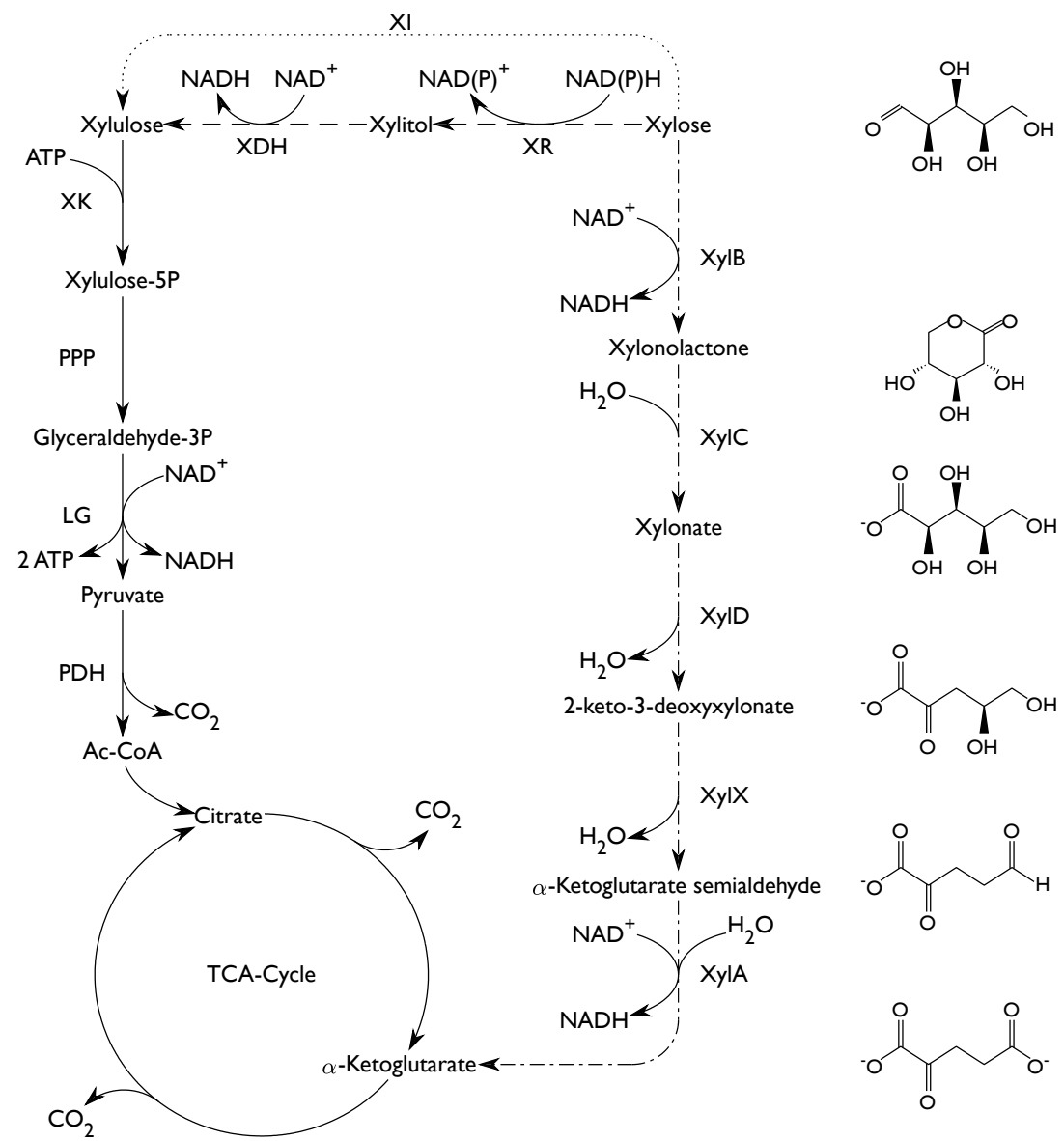

Figure 1. Schematic overview of the central carbon metabolism (solid lines) and the three xylose degradation pathways, the oxido-reductive pathway (dashed lines), the isomerase pathway (dotted lines) and the Weimberg pathway (dash-dot lines). Weimberg pathway enzymes are labeled with the gene encoding for each enzyme. Abbreviations: $\mathrm{XR}-\mathrm{Xylose}$ Reductase, $\mathrm{XDH}-\mathrm{Xylitol}$ Dehydrogenase, XI-Xylose Isomerase, PPP_Pentose Phosphate Pathway, LG—Lower Glycolysis, PDH-Pyruvate Dehydrogenase. Adapted from [13,14].

Xylose, a pentose sugar, is an important building block in hemicellulose, especially in hardwood and herbaceous plants where it can constitute up to $20 \%$ of the dry matter [15]. Efficient xylose utilization is thus an important goal in lignocellulose-based biorefineries. Natural xylose utilizing ability is missing in several industrial host organisms, such as the yeast Saccharomyces cerevisiae, or the bacterium Corynebacterium glutamicum and heterologous pathways have to be introduced to enable xylose utilization $[13,14]$. Most frequently, either the oxido-reductive (xylose reductase and xylitol dehydrogenase - $\mathrm{XR} / \mathrm{XDH}$ ) pathway or the isomerase (XI) pathway have been used for this purpose (Figure 1). Both pathways convert xylose into xylulose, which is further metabolized in the pentose phosphate pathway (PPP), followed by conversion in the lower glycolysis to yield pyruvate. 
Pyruvate is an important node, from which many products can be formed, e.g., ethanol, acetate and lactate. Since there is a net gain in ATP in the lower glycolysis these products can be formed anaerobically, but most of them result in a loss of carbon as $\mathrm{CO}_{2}$. In aerobic processes, the carbon can instead be directed to the tricarboxylic acid cycle (TCA-cycle) to produce di- or tricarboxylic acids.

Recently, the Weimberg pathway has received significant interest from the scientific community as an alternative to the oxido-reductive and isomerase pathways, due to the fact that glycolysis is by-passed and no carbon is lost from decarboxylation. The end-product of the Weimberg pathway is $\alpha$-ketoglutarate, an intermediate in the TCA-cycle, which makes the pathway an interesting option for production of carboxylic acids. The Weimberg pathway originating from C. crescentus has been established in Pseudomonas putida S12 [16] and in Corynebacterium glutamicum [13] enabling growth on xylose as the sole carbon source. In the study by Radek and co-workers, this was done as a step towards production of $\alpha$-ketoglutarate or derivatives of $\alpha$-ketoglutarate (e.g., L-glutamate) without carbon loss via the normal route through glycolysis. There have also been studies where only parts of the Weimberg pathway have been introduced, in order to produce the intermediate compound xylonate using both Escherichia coli $[17,18]$ and S. cerevisiae [19].

The Weimberg pathway clearly represents a fundamentally different entry port of xylose in comparison to the more commonly used XR/XDH or XI pathways. However, despite the considerable interest in the heterologous expression of the Weimberg pathway, there are surprisingly few studies on the physiology of the natural host organism itself. Transcriptional profiling of $C$. crescentus grown on glucose and xylose has been reported [6] as well as protein synthesis during growth on glucose and gluco-oligosaccharides [9], but a physiological characterization of $C$. crescentus grown on xylose, glucose and arabinose is in fact lacking.

In the present study, the growth of $C$. crescentus on three different carbon source, xylose, glucose and arabinose, was assessed. Product formation and specific growth rates were determined in shake flask and bioreactor cultivations. Furthermore, the activity of the dehydrogenase enzyme, encoded by $x y l B$ was determined in crude cell extracts. Also, the activity of the Weimberg pathway downstream of xylonate, measured as the combined activity of the three enzymes encoded by $x y l D, x y l X$ and $x y l A$, was determined. These results give information on the working Weimberg pathway in a native host, and may guide metabolic engineering work for efficient heterologous expression of the Weimberg pathway from C. crescentus in other hosts.

\section{Results}

\subsection{Growth in Shake Flasks}

Growth characteristics of $C$. crescentus were investigated for three substrates-glucose, xylose, and arabinose each at three concentrations 5, 10, and $20 \mathrm{~g} \mathrm{~L}^{-1}$ (Figure 2). The highest optical density $\left(\mathrm{OD}_{620}\right)$ was achieved on glucose followed by xylose, whereas growth on arabinose resulted in the lowest $\mathrm{OD}$ of the tested substrates. Using glucose as substrate, specific growth rates at 5 and $10 \mathrm{~g} \mathrm{~L}^{-1}$ were similar $\left(0.14 \mathrm{~h}^{-1}\right.$ and $0.15 \mathrm{~h}^{-1}$, respectively) and as expected a higher final OD was obtained for $10 \mathrm{~g} \mathrm{~L}^{-1}$. The sudden drop in OD at the end of the $5 \mathrm{~g} \mathrm{~L}^{-1}$ glucose experiment was most likely due to biofilm formation and not a sudden decrease in biomass, since aggregated cells could be seen on the sides of the flask at the gas-liquid interface. At $20 \mathrm{~g} \mathrm{~L}^{-1}$ the lag phase was considerably longer and the specific growth rate was lower, $0.12 \mathrm{~h}^{-1}$. The culture had not reached the stationary phase when the experiment was terminated after $200 \mathrm{~h}$. Slightly lower specific growth rates were found using xylose as a substrate, $0.10 \mathrm{~h}^{-1}$ at $5 \mathrm{~g} \mathrm{~L}^{-1}$ and $0.11 \mathrm{~h}^{-1}$ at $10 \mathrm{~g} \mathrm{~L}^{-1}$. At $20 \mathrm{~g} \mathrm{~L}^{-1}$ the specific growth rate was markedly affected and reached only $0.05 \mathrm{~h}^{-1}$. In addition, the final OD was lower at all substrate concentrations, especially at $20 \mathrm{~g} \mathrm{~L}^{-1}$. Arabinose was in all aspects a poorer substrate than glucose and xylose, resulting in longer lag phase, lower growth rate, and lower final OD. 

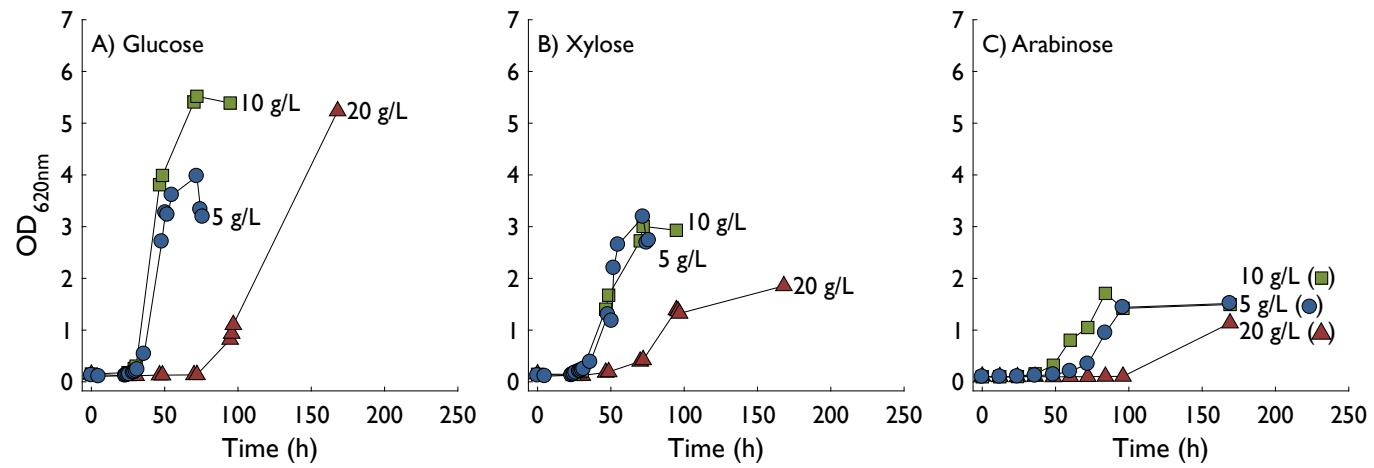

Figure 2. Optical density $(620 \mathrm{~nm})$ of cultures of C. crescentus in defined M2 medium supplemented with glucose (A), xylose (B) or arabinose (C) as substrate. Growth was monitored in three levels of substrate, $5 \mathrm{~g} \mathrm{~L}^{-1}$ (circles), $10 \mathrm{~g} \mathrm{~L}^{-1}$ (squares) or $20 \mathrm{~g} \mathrm{~L}^{-1}$ (triangles). Data shown in this figure represents experiments performed in biological duplicates.

\subsection{Enzyme Activity}

Enzyme activities were assayed in crude cell extract from shake flask cultures. The activity of $\mathrm{XylB}$ was assessed, as well as the combined activity of $\mathrm{XylD}$, XylX, and XylA, denoted as XylDXA. XylB activity was assesed by addition of xylose as a substrate and monitoring the formation of NADH. Since the assays were performed with crude cell extract, all enzymes in the Weimberg pathway are present in the reaction mixture. This means that the effect of product inhibition is reduced since the following enzymes in the pathway continuously convert the product of XylB to the final product. It also means that there might be some contribution to NADH formation by the final enzyme, $\mathrm{XylA}$. Since neither XylD nor XylX activity results in any product measurable with spectroscopy, XylA activity was used to monitor the conversion of xylonate to the final product, assuming that no accumulation of intermediate metabolites occurred. As can be seen in Figure 3, all the assayed Weimberg pathway enzymes are synthesised in the presence of both xylose (Xyl) and arabinose (Ara), but not in the presence of glucose (Glu). In addition, the results show XylB activity using both xylose and arabinose as substrate, independent of which substrate the cells were grown on. The negative value for XylDXA activity in cells grown on glucose does not imply reverse activity but was rather an effect of background activity in the sample.

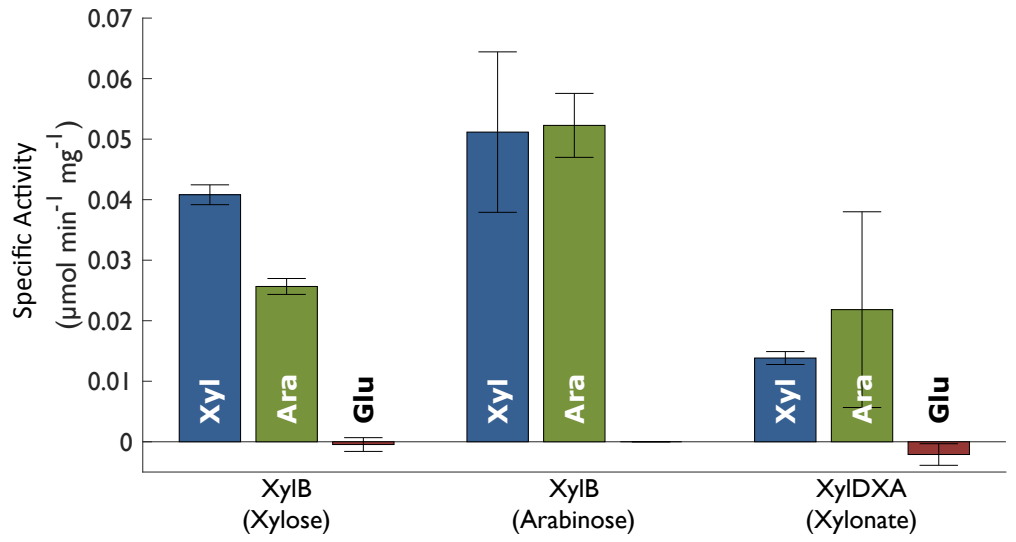

Figure 3. Enzyme activity in crude cell extract form C. crescentus grown on xylose (Xyl), arabinose (Ara) or glucose $(\mathrm{Glu})$. Xylose dehydrogenase $(\mathrm{XylB})$ was assayed with both xylose and arabinose as substrate and the compound activity of three enzymes (XylDXA), xylonate dehydratase (XylD), 2-keto-3-deoxyxylonate dehydratase (XylX) and $\alpha$-ketoglutarate semialdehyde dehydrogenase (XylA). Substrates are indicated within round brackets. Error bars represent standard deviation. 


\subsection{Characterization in Bioreactors}

Growth and product formation was studied in bioreactor experiments using either $10 \mathrm{~g} \mathrm{~L}^{-1}$ glucose or xylose as substrate (Figure 4A,B). Growth was analyzed by measurement of optical density and cell dry weight. In addition, the fermentation broth was analyzed for metabolites using liquid chromatography. In the experiment with glucose as a substrate, biomass was the only product found in the medium. In contrast, $\alpha$-ketoglutarate was found in the fermentation broth of the experiment with xylose. In the bioreactor experiment with glucose as a substrate the specific growth rate was 0.13-0.15 $\mathrm{h}^{-1}$, which was similar to what was found in shake flask experiments at the same substrate concentration. In contrast to the shake flask, there was no lag-phase in the bioreactor. However, glucose was not depleted during the duration of the bioreactor experiment, as was the case in shake flasks, and consequently the final OD was markedly lower. The specific growth rate in the xylose bioreactor was $0.05-0.08 \mathrm{~h}^{-1}$ which was lower than that in the corresponding shake flask experiment. Similarly to the glucose bioreactor, growth stopped before substrate was depleted. However, consumption of xylose did not cease and substantial amounts of $\alpha$-ketoglutarate were formed at a specific production rate of $0.02-0.03 \mathrm{~g} \mathrm{gDW}^{-1} \mathrm{~h}^{-1}$. The final $\alpha$-ketoglutarate yield was $0.32-0.43 \mathrm{~g} \mathrm{~g}^{-1}$. Bioreactor experiments were also carried out with $5 \mathrm{~g} \mathrm{~L}^{-1}$ xylose (Figure 4C,D). After the initial lag-phase of about $36 \mathrm{~h}$, xylose consumption and growth started. During the exponential growth phase, the specific growth rate varied from 0.04 to $0.13 \mathrm{~h}^{-1}$ and the specific xylose consumption rate varied between 0.14 and $0.34 \mathrm{~g} \mathrm{gDW}^{-1} \mathrm{~h}^{-1}$. In all cases, formation of $\alpha$-ketoglutarate started after growth had begun and continued after cessation of growth, resulting in a yield of $0.25-0.43 \mathrm{~g} \mathrm{~g}^{-1}$. In one case, where xylose was completely consumed, re-consumption of $\alpha$-ketoglutarate occurred, although without growth during the consumption phase.
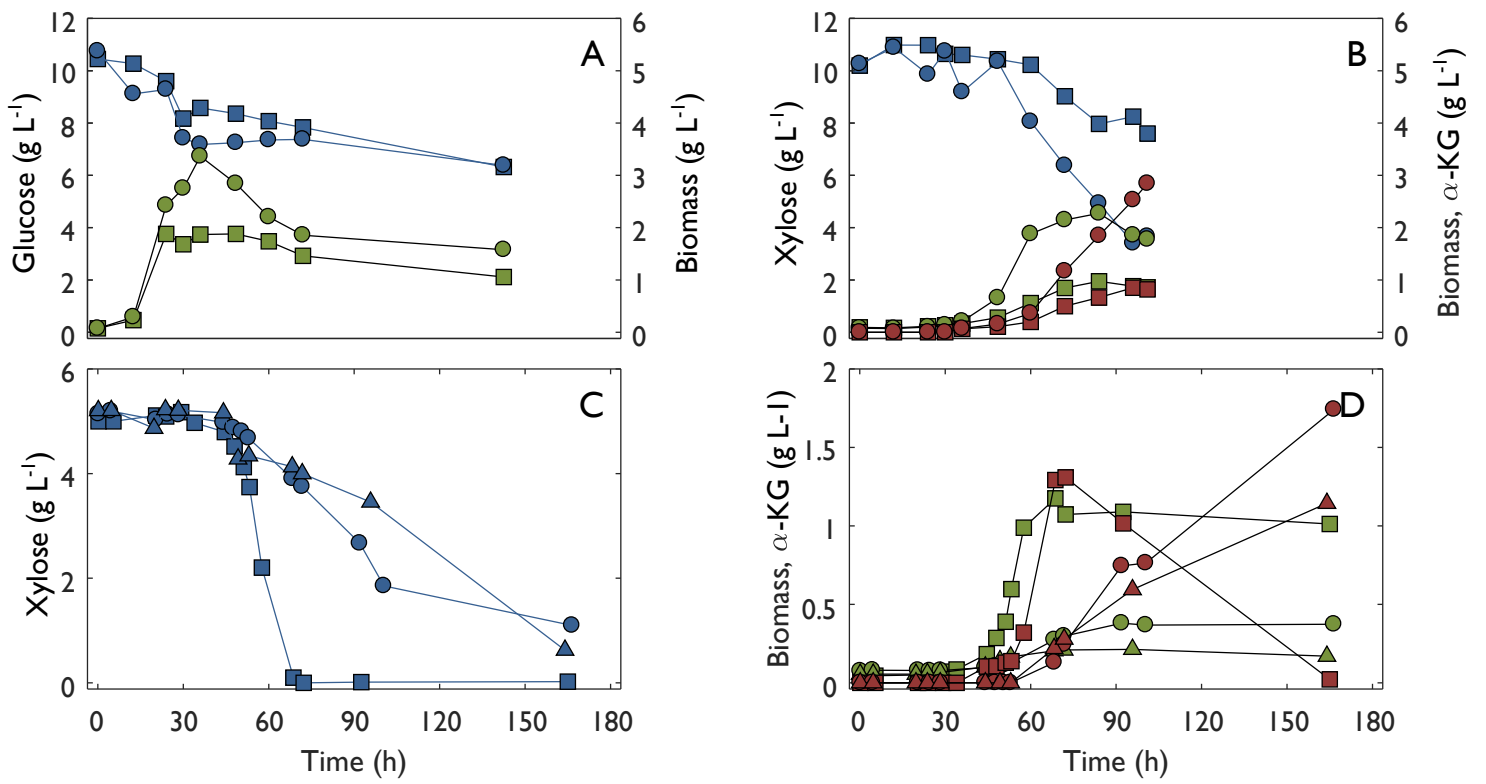

Figure 4. Metabolite profile from bioreactor experiments with C. crescentus in three conditions. The substrate was $10 \mathrm{~g} \mathrm{~L}^{-1}$ of glucose (A), $10 \mathrm{~g} \mathrm{~L}^{-1}$ of xylose $(\mathbf{B})$ or $5 \mathrm{~g} \mathrm{~L}^{-1}$ of xylose (C,D). Substrate is marked with blue symbols, biomass with green symbols and $\alpha$-ketoglutarate with red symbols. Circles, squares and triangle are used to distinguish between different replicates of the experiment.

\section{Discussion}

The results from shake flask experiments suggested that glucose is a better substrate than xylose in terms of specific growth rate and final biomass concentration. However, growth on xylose was only slightly slower, indicating that the Weimberg pathway is almost as efficient as the Entner-Doudoroff pathway, which is used by C. crescentus [11], in terms of providing energy and biosynthetic precursors 
for growth. The expression of the Weimberg pathway was found to be regulated, since the Weimberg pathway genes were expressed when grown on xylose but not on glucose. These findings agree with previous reports by Stephens and co-workers [11]. In the same work, these authors state that the Weimberg pathway may be involved in arabinose metabolism, even though the affinity for arabinose of XylB is much lower than xylose. However, they state that there may also be other ways for utilization of arabinose in C. crescentus. In the present study, it was found that both xylose and arabinose indeed trigger expression of the Weimberg pathway when provided in the growth medium. Additionally, XylB activity in crude cell extract was found using both xylose and arabinose, regardless of which of the two substrates was used to cultivate the cells. These findings together give strong support to the hypothesis that both xylose and arabinose are metabolized via the Weimberg pathway by the same enzymes. Although it cannot be ruled out that the NADH formation in presence of arabinose arose from other enzymes than $\mathrm{XylB}$, the fact that this activity is induced by both xylose and arabinose makes it likely that it is one and the same enzyme, i.e., XylB.

A common feature for all substrates was the considerably longer lag phase in experiments with $20 \mathrm{~g} \mathrm{~L}^{-1}$ of substrate. The mechanism behind the inhibited growth is probably not substrate inhibition, but rather low osmotolerance since experiments at elevated salt concentrations $\left(6 \mathrm{~g} \mathrm{~L}^{-1}\right)$ resulted in complete inhibition of growth. This fits well with the fact that the natural habitat of the organism is fresh water, which is an environment characterized by low concentration of solutes. It has been found that the sensitivity to osmotic stress of C. crescentus is due to an inability to accumulate intracellular solutes in respose to the osmotic stress [20].

An interesting finding of this study was that C. crescentus grew better in shake flasks than bioreactors on both $10 \mathrm{~g} \mathrm{~L}^{-1}$ glucose and $10 \mathrm{~g} \mathrm{~L}^{-1}$ xylose. The maximum growth rate did not differ much between shake flasks and bioreactors for glucose, but for xylose the specific growth rate was clearly lower. For both substrates, the final OD was also significantly lower in the bioreactors. There was a substantial variability in the growth experiments. A possible explanation for this could be that $C$. crescentus may be sensitive to aeration. The aeration in shake flasks is much lower than in bioreactors, and in the initial bioreactor experiments preceding those described in this paper higher aeration was used, resulting in very slow or even complete absence of growth on both glucose and xylose. Therefore, a control strategy where aeration of the bioreactor was controlled by the dissolved oxygen tension had to be implemented. Furthermore, the xylose concentration was lowered to $5 \mathrm{~g} \mathrm{~L}^{-1}$ to enable complete substrate depletion. In one out of three cases, the growth rate even exceeded the rates found in shake flasks. However, also in these experiments a high variability was found, indicating that the environment in a bioreactor is unfavorable for growth of C. crescentus even at minimal sparging and low stirrer rates.

In the bioreactor experiments with xylose, significant amounts of $\alpha$-ketoglutarate was found in the fermentation broth, and the formation of $\alpha$-ketoglutarate coincides with cessation of growth. This implies that, as long as the cells are growing, the rate of $\alpha$-ketoglutarate consumption by the TCA-cycle and amino acid synthesis matches the production of $\alpha$-ketoglutarate in the Weimberg pathway. However, as growth ceases, the production of $\alpha$-ketoglutarate in the Weimberg pathway is higher than the consumption, resulting in extracellular accumulation of $\alpha$-ketoglutarate. The yield of $\alpha$-ketoglutarate on xylose was high, reaching up to $0.43 \mathrm{~g} \mathrm{~g}^{-1}$ after growth had ceased. This is evidence that overflow metabolism on xylose occurs in C. crescentus as the $\alpha$-ketoglutarate otherwise would have been respired to produce ATP for maintenance.

The medium from bioreactor experiments was analysed for extracellular metabolites using both HPLC and UHPLC methods and no measurable amounts of any metabolite apart from xylose and $\alpha$-ketoglutarate were found. A mass balance on xylose was calculated with the sum of biomass, $\mathrm{CO}_{2}$ and $\alpha$-ketoglutarate, which amounted to $104 \%$, supporting the conclusion that no other major formation of metabolites occurred.

The maximum specific growth rate of C. crescentus on xylose was $0.13 \mathrm{~h}^{-1}$ which can be compared to that of engineered strains where the Weimberg pathway from $C$. crescentus has been 
expressed in other organisms. For example, C. glutamicum expressing the full Weimberg pathway from $C$. crescentus was reported to have a maximum specific growth rate of $0.07 \mathrm{~h}^{-1}$ on xylose as a sole carbon and energy source [13], which is in the same range as C. crescentus itself. In another example, the full Weimberg pathway from C. crescentus was expressed in P. putida [16] resulting in a maximum specific growth rate of $0.21 \mathrm{~h}^{-1}$ when using xylose as a sole carbon and energy source. In that study, the activity of the Weimberg pathway enzymes were assayed. The activity of XylB was found to be $0.829 \mu \mathrm{mol} \mathrm{min}{ }^{-1} \mathrm{mg}^{-1}$ which is more than twenty times higher than what we report for C. crescentus in this study $\left(0.0408 \mu \mathrm{mol} \mathrm{min}^{-1} \mathrm{mg}^{-1}\right)$. The activity of XylDXA was found to be $0.0259 \mu \mathrm{mol} \mathrm{min}{ }^{-1} \mathrm{mg}^{-1}$ which correlates well with the XylDXA activity obtained in our study $\left(0.0138 \mu \mathrm{mol} \mathrm{min}{ }^{-1} \mathrm{mg}^{-1}\right)$. This unbalance of activity in the engineered P. putida compared to the natural levels in $C$. crescentus may be one explanation to why the engineered organism overproduces xylonate. Compared to the engineered hosts, no intermediate metabolites, such as xylonate, were found in the fermentation broth from experiments with C. crescentus. This indicates that the activities of the enzymes in the pathway are finely balanced to achieve complete conversion of xylose to $\alpha$-ketoglutarate.

In conclusion, this study clearly shows that the Weimberg pathway is expressed and functioning in C. crescentus growing on xylose and most likely also on arabinose. The growth rate on xylose was close to the growth rate on glucose. Non-growing cells produced $\alpha$-ketoglutarate at high yields without formation of other metabolites. The slow growth of $C$. crescentus, its sensitivity to high concentrations of substrates and incompatibility with bioreactor cultivation, makes it unsuitable as a production organism for biorefinery purposes, justifying the efforts in the field of metabolic engineering attempting to introduce the Weimberg pathway in more suitable production organisms. The results of this study may prove valuable when introducing the Weimberg pathway in such organisms.

\section{Materials and Methods}

\subsection{Microorganism}

Caulobacter crescentus CB2 (DSM-4727) was purchased from DSMZ (Braunschweig, Germany) and kept frozen at $-80^{\circ} \mathrm{C}$ in glycerol stock.

\subsection{Medium Composition}

Two types of medium were used, a rich medium based on peptone and yeast extract (PYE) and a defined M2 medium [21]. PYE consisted of $2 \mathrm{~g} \mathrm{~L}^{-1}$ peptone, $1 \mathrm{~g} \mathrm{~L}^{-1}$ yeast extract, $0.8 \mathrm{mM} \mathrm{MgSO}_{4}$, and $0.5 \mathrm{mM} \mathrm{CaCl}_{2}$. The medium was sterilized at $121^{\circ} \mathrm{C}$ for $20 \mathrm{~min}$ in an autoclave. The defined $\mathrm{M} 2$ medium consisted of $1.74 \mathrm{~g} \mathrm{~L}^{-1} \mathrm{Na}_{2} \mathrm{HPO}_{4}, 1.06 \mathrm{~g} \mathrm{~L}^{-1} \mathrm{KH}_{2} \mathrm{PO}_{4}, 0.5 \mathrm{~g} \mathrm{~L}^{-1} \mathrm{NH}_{4} \mathrm{Cl}, 0.5 \mathrm{mM} \mathrm{MgCl}$, $0.5 \mathrm{mM} \mathrm{CaCl}_{2}, 10 \mu \mathrm{M} \mathrm{FeSO}_{4}$ and $8 \mu \mathrm{M}$ ethylenediaminetetraacetic acid (EDTA). A $10 \times$ concentrated stock solution of $\mathrm{Na}_{2} \mathrm{HPO}_{4}, \mathrm{KH}_{2} \mathrm{PO}_{4}$ and $\mathrm{NH}_{4} \mathrm{Cl}$ was prepared and sterilized separately. The other minerals were prepared and sterilized separately, as three $100 \times$ concentrated solutions, one containing $\mathrm{MgCl}_{2}$, the second containing $\mathrm{CaCl}_{2}$, and the third containing $\mathrm{FeSO}_{4}$ and EDTA. Glucose, xylose and arabinose were prepared and sterilized separately as $200 \mathrm{~g} \mathrm{~L}^{-1}$ stock solutions. Prior to each experiment the components were mixed in the appropriate amounts and sterile, deionized water was used to dilute the solutions to reach the final concentration. All solutions were sterilized by autoclavation $\left(121{ }^{\circ} \mathrm{C}, 20 \mathrm{~min}\right)$ except the $\mathrm{FeSO}_{4}$ solution which was filter sterilized using $0.2 \mu \mathrm{m}$ syringe filters.

\subsection{Shake-Flask Cultivation}

Frozen stocks were revived in PYE medium in $250 \mathrm{~mL}$ E-flasks with $50 \mathrm{~mL}$ working volume. Growth tests were performed in M2 medium with 5, 10, or $20 \mathrm{~g} \mathrm{~L}^{-1}$ of glucose, xylose, or arabinose, a total of nine experiment conditions. Also here, $250 \mathrm{~mL}$ flasks with $50 \mathrm{~mL}$ working volume were used. Growth test experiments were inoculated from flasks with PYE medium. 
The inoculation volume corresponded to an initial OD of 0.1 , usually around $10 \%$ of the volume. All experiments were performed in duplicates at $33^{\circ} \mathrm{C}$ and $200 \mathrm{rpm}$ in an orbital shaker incubator (Kuhner, Basel, Switzerland).

\subsection{Bioreactor Cultivation}

Bioreactor experiments were performed in 2.5 L bioreactors (B. Braun International, Melsungen, Germany) with 1L working volume. The medium consisted of M2 medium supplemented with either glucose $10 \mathrm{~g} \mathrm{~L}^{-1}$, xylose $10 \mathrm{~g} \mathrm{~L}^{-1}$ or xylose $5 \mathrm{~g} \mathrm{~L}^{-1}$. Temperature was set at $33^{\circ} \mathrm{C}$ and the reactor was agitated with two Rushton turbines at $150 \mathrm{rpm}$. In experiments with $10 \mathrm{~g} \mathrm{~L}^{-1}$ substrate aeration was set to $0.1 \mathrm{vvm}$ (volume of air per volume of liquid and minute). In experiments with $5 \mathrm{~g} \mathrm{~L}^{-1} \mathrm{xylose}_{\text {, }}$ aeration was controlled using dissolved oxygen tension (DOT) signal as input, maintaining a minimum DOT of $50 \%$. Stirrer speed was manually increased if aeration rate exceeded $0.5 \mathrm{vvm}$, but not more than $350 \mathrm{rpm}$. A $3 \mathrm{M}$ solution $\mathrm{NaOH}$ was used to control $\mathrm{pH}$ which was set at 6.5. Bioreactors were inoculated with cells that had been grown in M2 medium to reach late exponential phase and then centrifuged $(3000 \times g$, for $15 \mathrm{~min})$ to remove the spent medium. The amount of cells used to inoculate the bioreactor corresponded to an initial OD of 0.1 .

\subsection{Biomass Measurements}

Cell dry weight (CDW) was measured by centrifugation $(2 \mathrm{~min}$ at $12,000 \times \mathrm{g})$ of $3 \times 2 \mathrm{~mL}$ of medium from late exponential phase, to obtain a cell pellet. The supernatant was discarded and the cell pellet resuspended in $0.9 \%$ saline. After a second centrifugation, the cell pellet was resuspended in deionized water and transferred to a pre-dried and pre-weighed glass tube which was incubated at $105^{\circ} \mathrm{C}$ for $16-24 \mathrm{~h}$. After cooling down to room temperature in a desiccator the tubes were weighed to determine the cell dry weight. Optical density was measured at $620 \mathrm{~nm}$ using a spectrophotometer. One unit of optical density corresponded to $0.504 \mathrm{~g} \mathrm{~L}^{-1} \mathrm{CDW}$. Maximum growth rate was estimated using Equation (1) on the data points forming the steepest slope of the growth curve.

$$
\mu=\frac{\ln \left(\frac{x_{2}}{x_{1}}\right)}{t_{2}-t_{1}}
$$

\subsection{Analyses of Sugars and Organic Acids}

Extracellular metabolites were analyzed on an HPLC system (Waters, Milford, MA, USA) after filtration of supernatant samples $(0.2 \mu \mathrm{m}$ cellulose acetate filters). Sugars were analyzed on a Bio-Rad Aminex HPX-87P column (Hercules, CA, USA) using ultra-pure water as mobile phase at a flow rate of $0.6 \mathrm{~mL} \mathrm{~min}{ }^{-1}$. Column temperature was $85^{\circ} \mathrm{C}$ and an refractive index detector (RI) was used for detection. Organic acids were analyzed on a Bio-Rad Aminex HPX-87H column using $10 \mathrm{mM} \mathrm{H}_{2} \mathrm{SO}_{4}$ as mobile phase at flow rate of $0.6 \mathrm{~mL} \mathrm{~min}{ }^{-1}$. Acids were detected using an UV-detector at $210 \mathrm{~nm}$. Samples were also analyzed for xylonate on a UHPLC system (Waters, Milford, MA, USA) equipped with an amide column and evaporative light scattering detector (ELSD, Waters, Milford, MA, USA) according to the method described by Almqvist and co-workers [22].

\subsection{Enzymatic Assays}

Cells were harvested at late exponential phase of growth in PYE supplemented with either xylose, arabinose or glucose. The cell samples were centrifuged at $3000 \times g, 8{ }^{\circ} \mathrm{C}$ for 15 min (Hermle Z513K, Wehingen, Germany). The supernatant was removed from the cell pellet and Yeast Protein Extraction Reagent (Y-PER; Thermo Fisher Scientific, Pierce Biotechnology, Waltham, MA, USA) was added at a proportion of $4 \mu \mathrm{L}$ per $\mathrm{mg}$ cell pellet. The cells were resuspended in the reagent and incubated at $30 \mathrm{rpm}, 25^{\circ} \mathrm{C}$ for 20 min using a tilt board (Swelab Mixer 440, Boule, Spånga, Sweden). After incubation, the cell extract was centrifuged at $14,000 \times g, 25^{\circ} \mathrm{C}$ for 10 min to remove cell debris. The supernatant containing the extracted protein was subsequently used in the enzyme 
assays. A fraction of supernatant was transferred to a new Eppendorf tube and kept at $-20{ }^{\circ} \mathrm{C}$ for protein determination. Protein determination was done using the Bradford method [23] using bovine serum albumin (BSA) as standard. The enzymes encoded by XylB and XylA have $\mathrm{NAD}^{+}$as a cofactor and hence the enzyme activity is directly proportional to reduction of NAD ${ }^{+}$to NADH. The activity of XylB was measured using either xylose or arabinose as substrate. The activity of the dehydratases encoded by XylD and XylX were not directly measured but estimated from the sequential conversion of xylonate by the enzymes encoded by XylD, XylX and XylA, denoted XylDXA in the assays. The composition of the three reaction mixtures used for the assays is shown in Table 1 [16,24]. The activity of XylA was not assayed as $\alpha$-ketoglutaric semialdehyde, the natural substrate of enzyme XylA was not commercially available. All components except the substrates were mixed together with the cell extract in the wells of the microtiter plate. Background activity in the sample was monitored and when stable the reaction was then initiated by addition of the substrate. NADH formation was continuously monitored at $340 \mathrm{~nm}$ during $10 \mathrm{~min}$ at $30^{\circ} \mathrm{C}$ in a thermostated microtiter plate reader (Ascent Multiscan, Thermo Fisher Scientific, Waltham, MA, USA). The enzyme activity was estimated by linear fitting of the absorbance measurements where the steepest linear slope, at least $1 \mathrm{~min}$ long was used.

Table 1. Stock solution composition for the enzyme assays.

\begin{tabular}{cccc}
\hline & XylB & XylB & XylDXA \\
\hline Tris-HCl, $\mathrm{pH} 8.0(\mathrm{mM})$ & 100.0 & 100.0 & 100.0 \\
$\mathrm{MgCl}_{2}(\mathrm{mM})$ & 2.0 & 2.0 & 10.0 \\
$\mathrm{NAD}^{+}(\mathrm{mM})$ & 2.0 & 2.0 & 2.0 \\
Xylose $(\mathrm{mM})$ & 83.3 & - & - \\
Arabinose $(\mathrm{mM})$ & - & 83.3 & - \\
Xylonate $(\mathrm{mM})$ & - & - & 80.0 \\
\hline
\end{tabular}

Author Contributions: H.A., L.W. and G.L. conceived and designed the study. H.A., S.J.G., C.T. and L.W. performed the experiments and analysed the data. H.A. wrote the manuscript.

Funding: This work was part of the project XyloCut and financed within the ERA-Net for Applied Systems Biology.

Acknowledgments: The partners of the XyloCut project are acknowledged for their valuable input to this work.

Conflicts of Interest: The authors declare no conflict of interest.

\section{Abbreviations}

The following abbreviations are used in this manuscript:

$\begin{array}{ll}\text { CDW } & \text { Cell Dry Weight } \\ \text { DOT } & \text { Dissolved Oxygen Tension } \\ \text { HPLC } & \text { High Performance Liquid Chromatography } \\ \text { LG } & \text { Lower Glycolysis } \\ \text { NADH/NAD } & \text { Nicotinamide Adenine Dinucleotide (Reduced/Oxidized) } \\ \text { OD } & \text { Optical Density } \\ \text { PDH } & \text { Pyruvate dehydrogenase } \\ \text { PPP } & \text { Pentose Phosphate Pathway } \\ \text { TCA-Cycle } & \text { Tricarboxylic Acid Cycle } \\ \text { UHPLC } & \text { Ultra High Performance Liquid Chromatography } \\ \text { XDH } & \text { Xylulose Dehydrogenase } \\ \text { XI } & \text { Xylose Isomerase } \\ \text { XR } & \text { Xylose Reductase }\end{array}$




\section{References}

1. Henrici, A.T.; Johnson, D.E. Studies of Freshwater Bacteria: II. Stalked Bacteria, a New Order of Schizomycetes. J. Bacteriol. 1935, 30, 61-93. [PubMed]

2. Skerker, J.M.; Laub, M.T. Cell-cycle progression and the generation of asymmetry in Caulobacter crescentus. Nat. Rev. Microbiol. 2004, 2, 325-337. [CrossRef] [PubMed]

3. Curtis, P.D.; Brun, Y.V. Getting in the loop: Regulation of development in Caulobacter crescentus. Microbiol. Mol. Biol. Rev. MMBR 2010, 74, 13-41. [CrossRef] [PubMed]

4. Tsokos, C.G.; Laub, M.T. Polarity and cell fate asymmetry in Caulobacter crescentus. Curr. Opin. Microbiol. 2012, 15, 744-750. [CrossRef] [PubMed]

5. Nierman, W.C.; Feldblyum, T.V.; Laub, M.T.; Paulsen, I.T.; Nelson, K.E.; Eisen, J.; Heidelberg, J.F.; Alley, M.R.K.; Ohta, N.; Maddock, J.R.; et al. Complete genome sequence of Caulobacter crescentus. Proc. Natl. Acad. Sci. USA 2001, 98, 4136-4141. [CrossRef] [PubMed]

6. Hottes, A.K.; Meewan, M.; Yang, D.; Arana, N.; Romero, P.; McAdams, H.H.; Stephens, C. Transcriptional profiling of Caulobacter crescentus during growth on complex and minimal media. J. Bacteriol. 2004, 186, 1448-1461. [CrossRef] [PubMed]

7. Arellano, B.H.; Ortiz, J.D.; Manzano, J.; Chen, J.C. Identification of a dehydrogenase required for lactose metabolism in caulobacter crescentus. Appl. Environ. Microbiol. 2010, 76, 3004-3014. [CrossRef] [PubMed]

8. Zalatan, F.; Black, P. Characterization of long-chain fatty acid uptake in Caulobacter crescentus. Arch. Microbiol. 2011, 193, 479-487. [CrossRef] [PubMed]

9. Presley, G.N.; Payea, M.J.; Hurst, L.R.; Egan, A.E.; Martin, B.S.; Periyannan, G.R. Extracellular gluco-oligosaccharide degradation by Caulobacter crescentus. Microbiology 2014, 160, 635-645. [CrossRef] [PubMed]

10. Wichelecki, D.J.; Graff, D.C.; Al-Obaidi, N.; Almo, S.C.; Gerlt, J.A. Identification of the in Vivo Function of the High-Efficiency D-Mannonate Dehydratase in Caulobacter crescentus NA1000 from the Enolase Superfamily. Biochemistry 2014, 53, 4087-4089. [CrossRef] [PubMed]

11. Stephens, C.; Christen, B.; Fuchs, T.; Sundaram, V.; Watanabe, K.; Jenal, U. Genetic analysis of a novel pathway for D-xylose metabolism in Caulobacter crescentus. J. Bacteriol. 2007, 189, 2181-2185. [CrossRef] [PubMed]

12. Weimberg, R. Pentose oxidation by Pseudomonas fragi. J. Biol. Chem. 1961, 236, 629-635. [PubMed]

13. Radek, A.; Krumbach, K.; Gätgens, J.; Wendisch, V.F.; Wiechert, W.; Bott, M.; Noack, S.; Marienhagen, J. Engineering of Corynebacterium glutamicum for minimized carbon loss during utilization of D-xylose containing substrates. J. Biotechnol. 2014, 192, 156-160. [CrossRef] [PubMed]

14. Karhumaa, K.; Garcia Sanchez, R.; Hahn-Hägerdal, B.; Gorwa-Grauslund, M.F. Comparison of the xylose reductase-xylitol dehydrogenase and the xylose isomerase pathways for xylose fermentation by recombinant Saccharomyces cerevisiae. Microb. Cell Fact. 2007, 6, 5, doi:10.1186/1475-2859-6-5. [CrossRef] [PubMed]

15. Álvarez, C.; Reyes-Sosa, F.M.; Díez, B. Enzymatic hydrolysis of biomass from wood. Microb. Biotechnol. 2016, 9, 149-156. [CrossRef] [PubMed]

16. Meijnen, J.P.; De Winde, J.H.; Ruijssenaars, H.J. Establishment of oxidative D-xylose metabolism in Pseudomonas putida S12. Appl. Environ. Microbiol. 2009, 75, 2784-2791. [CrossRef] [PubMed]

17. Liu, H.; Valdehuesa, K.N.G.; Nisola, G.M.; Ramos, K.R.M.; Chung, W.J. High yield production of D-xylonic acid from D-xylose using engineered Escherichia coli. Bioresour. Technol. 2012, 115, 244-248. [CrossRef] [PubMed]

18. Cao, Y.; Xian, M.; Zou, H.; Zhang, H. Metabolic Engineering of Escherichia coli for the Production of Xylonate. PLoS ONE 2013, 8, e67305, doi:10.1371/journal.pone.0067305. [CrossRef] [PubMed]

19. Toivari, M.H.; Ruohonen, L.; Richard, P.; Penttilä, M.; Wiebe, M.G. Saccharomyces cerevisiae engineered to produce D-xylonate. Appl. Microbiol. Biotechnol. 2010, 88, 751-760. [CrossRef] [PubMed]

20. Kohler, C.; Lourenço, R.F.; Bernhardt, J.; Albrecht, D.; Schüler, J.; Hecker, M.; Gomes, S.L. A comprehensive genomic, transcriptomic and proteomic analysis of a hyperosmotic stress sensitive $\alpha$-proteobacterium. BMC Microbiol. 2015, 15, 71, doi:10.1186/s12866-015-0404-x. [CrossRef] [PubMed]

21. Ely, B. Genetics of Caulobacter crescentus. Methods Enzymol. 1991, 204, 372-384. [PubMed] 
22. Almqvist, H.; Sandahl, M.; Lidén, G. A rapid method for analysis of fermentatively produced D-xylonate using ultra-high performance liquid chromatography and evaporative light scattering detection. Biosci. Biotechnol. Biochem. 2017, 81, 1078-1080. [CrossRef] [PubMed]

23. Bradford, M. A rapid and sensitive method for the quantitation of microgram quantities of protein utilizing the principle of protein-dye binding. Anal. Biochem. 1976, 72, 248-254. [CrossRef]

24. Johnsen, U.; Dambeck, M.; Zaiss, H.; Fuhrer, T.; Soppa, J.; Sauer, U.; Schönheit, P. D-xylose degradation pathway in the halophilic archaeon Haloferax volcanii. J. Biol. Chem. 2009, 284, 27290-27303. [CrossRef] [PubMed]

(C) 2018 by the authors. Licensee MDPI, Basel, Switzerland. This article is an open access article distributed under the terms and conditions of the Creative Commons Attribution (CC BY) license (http://creativecommons.org/licenses/by/4.0/). 